\title{
Typical Iris Pearls in Lepromatous Leprosy
}

\author{
Archana Thool ${ }^{1}$, Kervi Mehta ${ }^{2}$ \\ 1, 2 Department of Ophthalmology, Jawaharlal Medical College, Datta Meghe Institute of Medical Sciences University, \\ Sawangi (Meghe), Wardha, Maharashtra, India.
}

\section{INTRODUCTION}

Leprosy (Hansen's disease) is a chronic granulomatous inflammatory disease caused by bacterium Mycobacterium leprae. Leprosy majorly affects the skin, peripheral nerves and eyes. In India, various estimates have suggested ocular complications to vary from 5 - $80 \%$ in leprosy. ${ }^{1,2}$ Depending on the immune system of the patient to bacteria, various ocular manifestations are seen. Ocular manifestations are seen more commonly in lepromatous leprosy, due to direct invasion by M. leprae, through the blood vessels. ${ }^{3}$ About 40 - $50 \%$ patients of leprosy have reversible blindness due to cataract.4

In patients diagnosed of leprosy, ocular manifestation seen are - lagophthalmos, madarosis, trichiasis, corneal exposure, iridocyclitis, corneal ulceration and scarring, episcleritis, scleritis, ocular hypotony, keratitis, iris atrophy, iritis, conjunctival and scleral leproma, uveitis, uveal effusion, retinal pearls, chorioretinitis, retinal detachment. ${ }^{5,6}$ In eye, Leprosy bacilli are likely to get lodge in the anterior segment of eye, as they are the coolest parts of the globe of the eye compared to posterior segment of eye. In the anterior segment, it particularly involves - the ciliary body and iris due to high vascularity. Clinically, it is seen as iris pearls, which are pathognomonic of leprosy. They are asymptomatic, 0.3 to $1.0 \mathrm{~mm}$ diameter, dull yellow in colour. They are seen at an early stage of the disease and are not associated with any inflammatory changes in the anterior chamber. ${ }^{7,8}$ Histologically, it consists of lepromatous bacilli packed within mononuclear cells or acid-fast material with accompanying foreign body reaction.

They are found around pupillary margins and may occur in deep iris stroma. Iris nodules are not dangerous, but they serve useful guide in diagnosis of ocular leprosy which may co-exist with signs of iridocyclitis. They may coalesce and become pinched off and drop into anterior chamber, where it is absorbed without causing inflammatory reaction. ${ }^{9}$ They never disappear in patient of leprosy who have completed the multidrug therapy for multibacillary leprosy, but remain dormant in arrested cases, which are composed of amorphous acid-fast material.
Corresponding Author:

Dr. Kervi Mehta,

Junior Resident,

Department of Ophthalmology,

Jawaharlal Medical College,

Datta Meghe Institute of

Medical Sciences University,

Sawangi (Meghe), Wardha,

Maharashtra, India

E-mail:kervi@gmail.com

DOI: $10.14260 /$ jemds/2021/36

How to Cite This Article:

Thool A, Mehta K. Typical iris pearls in lepromatous leprosy. J Evolution Med Dent Sci 2021;10(03):167-169, DOI: $10.14260 /$ jemds/2021/36

Submission 09-09-2020,

Peer Review 17-11-2020

Acceptance 23-11-2020,

Published 18-01-2021.

Copyright (C) 2021 Archana Thool et al. This is an open access article distributed under Creative Commons Attribution License [Attribution 4.0 International (CC BY 4.0)] 


\section{PRESENTATION OF CASE}

A 70-year-old male patient was referred from dermatology to ophthalmology outpatient department for diminution of vision in both the eyes for the last 6 - 8 months. The patient was a diagnosed case of Multibacillary Hansen's Disease (lepromatous leprosy) 10 years back, for which he received multidrug therapy consisting of rifampicin $600 \mathrm{mg}$ with clofazimine $300 \mathrm{mg}$ monthly and dapsone $100 \mathrm{mg} /$ day, clofazimine $50 \mathrm{mg} /$ day for duration of 1 year. No other positive systemic history.

No mutilations were detected in hands and feet. No neurological deficits and thickened nerves were present.

\section{Ocular Examination}
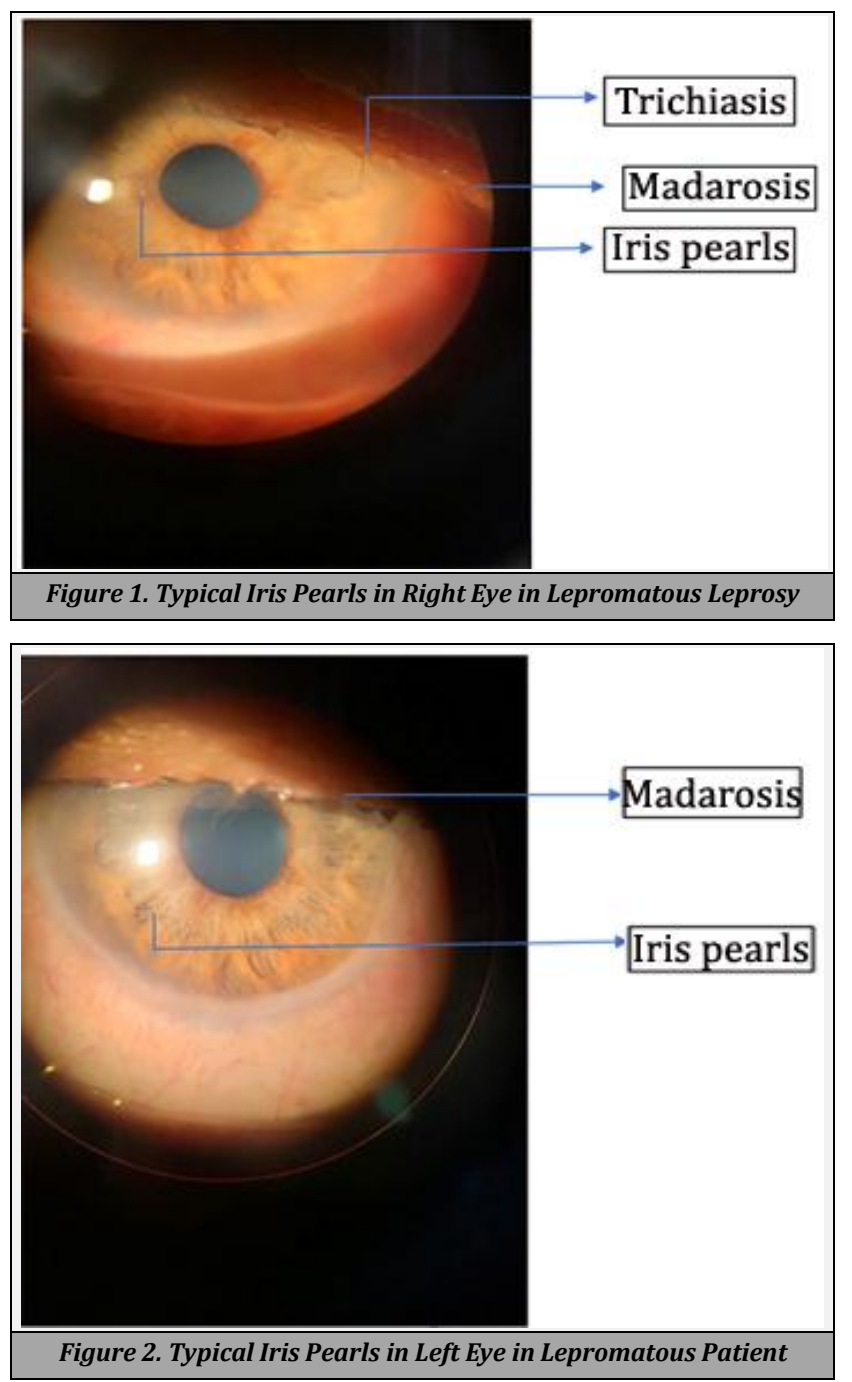

The best corrected visual acuity (BCVA) was 6 / 36 in right eye and 6 / 18 in left eye. Slit lamp bio microscopy in both eyes, revealed madarosis, trichiasis, and thickened lid margin. Cornea had diffuse nebular macular opacities not involving visual axis and corneal sensations were reduced in both eyes. Multiple minute pinpoint to pin head white spots suggestive of typical iris pearls were seen on the anterior surface of iris, not only near the pupillary margin but also in the peripheral part of iris associated with iris stromal atrophy. Left eye had nuclear sclerosis Grade 1 and right eye had nuclear sclerosis Grade 2. The intra-ocular pressure was $9 \mathrm{mmHg}$ in both the eyes. Fundus examination was within normal limits in both eyes.

Laboratory investigations showed haemoglobin of $13.8 \mathrm{~g} /$ $\mathrm{dL}$, leukocyte count of $8,200 / \mathrm{mm}^{3}$, platelet counts of 198,000 $/ \mathrm{mm}^{3}$ and ESR of $9 \mathrm{~mm}$, serum calcium was $9.0 \mathrm{mg} / \mathrm{dL}$. Chest $\mathrm{x}$-ray was normal. Patient was advised cataract extraction and accordingly patient underwent small incision cataract surgery with intra ocular lens implantation in our institute.

\section{DISCUSSION}

Leprosy is one of the diseases which causes frequent ocular complications as compared to other bacterial infections. ${ }^{10}$ Ocular Leprosy is a threatening condition leading to permanent vision loss. ${ }^{11}$ Most of the cases of ocular leprosy occur secondary to lepra reaction. Involvement of iris in lepromatous leprosy patients is one of the most important aspects as it leads to blindness. ${ }^{3}$ Iris pearls are seen in $4.6 \%$ of leprosy patients. ${ }^{11}$ These iris pearls are early manifestations of ocular leprosy, which require prompt diagnosis, adequate treatment and follow ups. Sometimes, larger nodules are seen in angle of anterior chamber and at pupillary margins which can eventually lead to poor prognosis. ${ }^{10,12}$ In our patient apart from pathognomonic iris pearls in both eyes, cataract was the only cause for decrease vision in both eyes. Hence, the patient underwent small incision cataract surgery with intra ocular lens implantation.

Since the patient was not willing to undergo surgery on left eye due to personal preference, patient was given best possible spectacle prescription at the end of 6 weeks for both the eyes. Even after completion of treatment, when patient is considered as cured, when skin biopsies are negative, it may relapse and continue to demonstrate ocular signs and symptoms. ${ }^{11}$ In the eyes of leprosy patients, bacilli remain in the iris macrophages even after multibacillary treatment has been completed. Their antigens are present in iris tissue which are responsible for recurrent reactions. This suggests regular ocular examination is important, even after systemic disease is treated.10,12 M. Leprae persists in fibrosed nerve and causes recrudescence of the disease. ${ }^{12}$ It can lead to acute exacerbations even after treatment, which can be ocular threatening condition,13,14,15 or it may be associated with posterior segment pathology like retinal pearls or chorioretinitis which can ultimately lead to permanent visual loss. Thus, the emphasis of active and regular follow-ups of such cases. ${ }^{16,17}$ is important. Hence, this patient was advised to follow up every 6 months after cataract extraction.

Financial or other competing interests: None.

Disclosure forms provided by the authors are available with the full text of this article at jemds.com.

\section{REFERENCES}

[1] Reddy SC, Raja BD, Achary NR. Survey of eye complications in leprosy in Prakasam District (Andhra Pradesh). Lepr India 1981;53(2):231-7. 
[2] Dutta LC, Das NC, Chatterjee BC, et al. Ocular lesions in leprosy. J Indian Med Assoc 1973;61(9):385-8.

[3] Ffytche TJ. Role of iris changes as a cause of blindness in lepromatous leprosy. Br J Ophthalmol 1981;65(4);231-9.

[4] Hogeweg M, Keunen JE. Prevention of blindness in leprosy and the role of the vision 2020 programme. Eye (Lond) 2005;19(10):1099-105.

[5] Choyce DP. Diagnosis and management of ocular leprosy. Br J Ophthalmol 1969;53(4):217-23.

[6] Daniel E, Koshy S, Joseph GA, et al. Ocular complications in incident relapsed borderline lepromatous and lepromatous leprosy patients in South India. Indian J Ophthamol 2003;51(2):155-9.

[7] Somerset EJ. Leprous lesions of the eye. Indian J Ophthalmol 1956;4(1):7-14.

[8] Hobbs HE, Choyce DP. The binding lesions of leprosy. Lepr Rev 1971;42(2):131-7.

[9] Daniel E, Ffytche TJ, Rao PSSS, et al. Incidence of ocular morbidity among multibacillary leprosy patients during a 2 year course of multidrug therapy. Br J Ophthalmol 2006;90(5):568-73.

[10] Malik A, Morris R, Ffytche TJ. The prevalence of ocular complications in leprosy patients seen in the United Kingdom over a period of 21 years. Eye (Lond) 2011;25(6):740-5.
[11] Grzybowski A, Nita M, Virmond M. Ocular leprosy. Clin Dermatol 2015;33(1):79-89.

[12] Ffytche TJ. The prevalence of disabling ocular complications of leprosy: a global study. Indian J Lepr 1998;70(1):49-59.

[13] Pareek A, Khandekar A, Acharya S, et al. Correlation between nephropathy and ophthalmic complications in cases of sickle cell anemia: an entangled association. Indian Journal of Medical Specialities 2019;10(2):72-5.

[14] Madhumita P, Daigavane S, Kalode V. Visual outcome after cataract surgery in rural hospital of Wardha District: a prospective study. Journal of Clinical and Diagnostic Research 2020;14(2):4-6.

[15] Daigavane S, Patkar P. To compare the changes in the corneal endothelium post phacoemulsification surgery with balanced salt solution vs. viscoelastic device. Journal of Clinical and Diagnostic Research 2019;13(12):1-4.

[16] Patkar P, Sune P. Evaluation of tear film functions preoperatively and postoperatively in cases with pterygium: a case control study. Journal of Clinical and Diagnostic Research 2020;14(1):NC10-13.

[17] Mukherji R, Sune P. Contrast sensitivity and visual acuity before and after Nd: YAG capsulotomy in patients with posterior capsular opacification: a prospective study. Journal of Clinical and Diagnostic Research 2020;14(3):58. 